\title{
Changes in patient characteristics in anti-tumour necrosis factor clinical trials for rheumatoid arthritis: results of an analysis of the literature over the past 16 years
}

\author{
Mahboob U Rahman, ${ }^{1-3}$ Jacqui Buchanan, ${ }^{4,5}$ Mittie K Doyle, ${ }^{1,2}$ Elizabeth C Hsia, ${ }^{1,2}$ \\ Timothy Gathany, ${ }^{4}$ Shreekant Parasuraman, ${ }^{4}$ Daniel Aletaha, ${ }^{6}$ Eric L Matteson, ${ }^{7}$ \\ Philip G Conaghan, ${ }^{8}$ Edward Keystone, ${ }^{9}$ Désireé van der Heijde, ${ }^{10}$ Josef $S$ Smolen ${ }^{6}$
}

${ }^{1}$ Centocor RøD, Inc, Malvern, Pennsylvania, USA

2University of Pennsylvania School of Medicine,

Philadelphia, Pennsylvania, USA

3*Pfizer, Inc, Collegeville,

Pennsylvania, USA

4Johnson \& Johnson

Pharmaceutical Services,

Malvern, Pennsylvania, USA

${ }^{5 *}$ Buchanan Biotech Consulting,

Mountain View, California, USA

${ }^{6}$ Medical University of

Vienna and Hietzing Hospital,

Vienna, Austria

${ }^{7}$ Mayo Clinic, Rochester,

Minnesota, USA

${ }^{8} \mathrm{NIHR}$ Leeds Musculoskeletal

Biomedical Research Unit,

University of Leeds, Leeds, UK

${ }^{9}$ University of Toronto, Toronto,

Ontario, Canada

${ }^{10}$ Leiden University Medical

Center, Leiden, The Netherlands

${ }^{*}$ Current affiliation of the author

\section{Correspondence to}

Josef S Smolen, Division of

Rheumatology, Department of

Internal Medicine III, Medical

University of Vienna and The

Center for Rheumatic Diseases,

Hietzing Hospital, Vienna

A-1090, Austria;

josef.smolen@wienkav.at

Accepted 1 May 2011

Published Online First

27 June 2011

\begin{abstract}
Objective To evaluate changes in baseline patient characteristics and entry criteria of randomised, controlled studies of tumour necrosis factor alpha (TNF $\alpha$ ) inhibitors in rheumatoid arthritis (RA) patients.
\end{abstract}

Methods A systematic literature review was performed using predefined inclusion criteria to identify randomised, double-blind, controlled trials that evaluated TNF $\alpha$ inhibitors in adult RA patients. Entry criteria and baseline clinical characteristics were evaluated over time for methotrexate-experienced and methotrexate-naive study populations. Enrolment start date for each trial was the time metric. The anchor time was the study with the earliest identifiable enrolment start date.

Results 44 primary publications (reporting the primary study endpoint) from 1993 to 2008 met the inclusion criteria. Enrolment start dates of August 1993 and May 1997 were identified as time anchors for the 37 methotrexate-experienced studies and the seven methotrexate-naive studies, respectively. In methotrexate-experienced trials, no significant change was observed over the years included in this study in any inclusion criteria (including swollen joint counts and C-reactive protein (CRP)), but a significant decrease over time was observed in the baseline swollen joint count, CRP and total Sharp or van der Heijde modified Sharp score, but not in baseline tender joint counts. In the methotrexate-naive studies, significant decreases over the years were observed in swollen joint and tender joint inclusion criteria, but not in baseline tender joint count, baseline CRP, CRP inclusion criteria or baseline total Sharp or van der Heijde modified Sharp score.

Conclusion Inclusion criteria and baseline characteristics of RA patients enrolled in studies of TNF $\alpha$ inhibitors have changed, with more recent trials enrolling cohorts with lower disease activity, especially in methotrexate-experienced trials.

In the early 1990s, there was a paradigm shift in the treatment of patients with rheumatoid arthritis (RA). ${ }^{1}$ Before this period, patients with RA were treated employing the 'pyramid' approach, in which non-steroidal anti-inflammatory drugs were used first, followed by disease-modifying antirheumatic drugs (DMARD) and steroids as the disease became more severe. The paradigm shift occurred when early intensive treatment was emphasised. Around this time, researchers also discovered the importance of proinflammatory cytokines in the pathogenesis of $\mathrm{RA}^{2}{ }^{3}$ which led to the first therapeutic use of cytokine inhibition to treat patients with RA. ${ }^{4}$ Several biological agents have now been approved by regulatory authorities in many countries for the treatment of patients with RA, including abatacept, adalimumab, certolizumab, etanercept, golimumab, infliximab, rituximab and tocilizumab.

The revised approach to the treatment of patients with RA over the past decade, which included early recognition ${ }^{5}$ and early DMARD start ${ }^{6}$ and the availability of an increasing number of treatment options, ${ }^{7} 8$ would be expected to result in fewer patients with severe disease in the population. ${ }^{9} 10$ Indeed, data of recent observational studies have suggested that the severity of RA has been decreasing over time. ${ }^{11} 12$ This has implications for clinical trials designed to evaluate the efficacy and safety of new therapeutics, ${ }^{13}$ however, it is not clear if this trend is the result of the disease becoming milder or the management of the disease is improving.

The purpose of this investigation was to evaluate the changes in inclusion criteria and baseline characteristics of patients in randomised controlled studies involving tumour necrosis factor alpha $(\mathrm{TNF} \alpha)$ inhibitors in patients with RA. We hypothesised that the disease activity of patients who participate in these studies has decreased over time, reflecting the larger trends in the population of patients as a whole.

\section{METHODS}

A systematic literature search was conducted using MEDLINE, EMBASE and the Cochrane Library (1988 to December 2008); clinical study reports (for golimumab only, these have since been published); ${ }^{14} 15$ citation lists, published systematic reviews and health technology assessments (1988-2008); internet sites for the US Food and Drug Administration, ClinicalTrials.gov and ClinicalStudyResults.org; and abstracts presented at the American College of Rheumatology (ACR) and the European League Against Rheumatism (EULAR) congresses (2004-8).

Databases were searched using specific search strings, which included some of the following key terms (synonyms and combinations): rheumatoid arthritis, tumour necrosis factor, tumour necrosis 
factor receptors, anti-tumour necrosis factor, adalimumab, etanercept, infliximab, certolizumab and golimumab. Search filters were used to identify randomised controlled trials in MEDLINE and EMBASE. Search limits (provided by Xcenda) were placed in MEDLINE and EMBASE to limit the studies to the date ranges indicated above, English language and humans (from Xcenda). The last search was conducted on 13 March 2009. Two reviewers independently inspected the titles and abstracts from the initial literature search to identify potentially relevant publications.

Predefined inclusion criteria were applied to the results of the literature search in a hierarchical manner. First, only randomised, double-blind, controlled trials were included that compared adalimumab, etanercept, certolizumab, golimumab or infliximab with any other agent, including placebo or alternative doses of the agent, in adult patients with RA. Second, only trials that were published in a peer-reviewed medical journal, available as a complete study report (for studies that had completed enrolment), or abstracts with primary endpoints that had been presented at ACR or EULAR congresses were included. Third, only trials with at least 4 weeks of follow-up and at least 25 patients were included. Singledose studies were included if the duration of follow-up exceeded 4 weeks.

Studies were excluded if they were designed to evaluate patients with conditions other than RA (eg, juvenile RA, Crohn's disease, psoriatic arthritis or ankylosing spondylitis), had non-randomised trial designs (eg, observational studies, open-label studies, non-comparative studies, case reports, systematic reviews or health technology assessments), or were preclinical (animal) or phase I studies. Studies that pooled patients from different disease cohorts were also excluded. All publications identified as potentially relevant by at least one reviewer were retrieved. The reviewers discussed publications that were

Table 1 Characteristics of primary publications for biological anti-TNF $\alpha$ agents

\begin{tabular}{|c|c|c|c|c|c|c|}
\hline Reference & Anti-TNF $\alpha$ agent & Trial name & Enrolment start date & Comparator & $\mathbf{N}$ & Patient population \\
\hline Elliott et al $1994^{16}$ & Infliximab & NA & 1993 & Placebo & 72 & MTX experienced \\
\hline Moreland et al $1997^{17}$ & Etanercept & NA & - & Placebo & 180 & MTX experienced \\
\hline Maini et al $1998^{18}$ & Infliximab & NA & 1994 & Placebo & 101 & MTX experienced \\
\hline Maini et al $1999^{19}$ & Infliximab & ATTRACT & 1997 & Placebo & 428 & MTX experienced \\
\hline Moreland et al 199920 & Etanercept & NA & - & Placebo & 234 & MTX experienced \\
\hline Weinblatt et al 199921 & Etanercept & NA & - & MTX & 89 & MTX experienced \\
\hline Bathon et al $2000^{22}$ & Etanercept & ERA & 1997 & MTX & 632 & MTX naive \\
\hline Kavanaugh et al $2000^{23}$ & Infliximab & NA & 1995 & Placebo & 28 & MTX experienced \\
\hline Choy et al $2002^{24}$ & Certolizumab & NA & - & Placebo & 36 & MTX experienced \\
\hline Furst et al $2003^{25}$ & Adalimumab & STAR & 2000 & Placebo & 636 & MTX experienced \\
\hline van de Putte et al $2003^{26}$ & Adalimumab & DE007 & 2001 & Placebo & 284 & MTX experienced \\
\hline Weinblatt et al $2003^{27}$ & Adalimumab & ARMADA & - & MTX & 271 & MTX experienced \\
\hline Keystone et al $2004^{28}$ & Adalimumab & DE019 & 2002 & MTX & 619 & MTX experienced \\
\hline van de Putte et al $2004^{29}$ & Adalimumab & DE011 & 2000 & Placebo & 544 & MTX experienced \\
\hline Genovese et al $2004^{30}$ & Etanercept & NA & - & Anakinra & 244 & MTX experienced \\
\hline Keystone et al $2004^{31}$ & Etanercept & NA & - & Placebo & 420 & MTX experienced \\
\hline Klareskog et al $2004^{32}$ & Etanercept & TEMPO & 2000 & MTX & 652 & MTX experienced \\
\hline Lan et al $2004^{33}$ & Etanercept & NA & 2000 & Placebo & 58 & MTX experienced \\
\hline St. Clair et al $2004^{34}$ & Infliximab & ASPIRE & 2000 & MTX & 1004 & MTX naive \\
\hline Johnsen et al $2006^{35}$ & Etanercept & NA & 1999 & Etanercept & 77 & MTX experienced \\
\hline Abe et al $2006^{36}$ & Infliximab & NA & 2000 & Placebo & 147 & MTX experienced \\
\hline Leirisalo-Repo et al $2006^{37}$ & Infliximab & NEO-RACO & 2005 & Placebo & 99 & MTX experienced \\
\hline Westhovens et al $2006^{38}$ & Infliximab & START & 2001 & Placebo & 1082 & MTX experienced \\
\hline Zhang et al $2006^{39}$ & Infliximab & NA & 2003 & Placebo & 173 & MTX experienced \\
\hline Breedveld et al $2006^{40}$ & Adalimumab & PREMIER & 2001 & MTX & 799 & MTX naive \\
\hline Kim et al $2007^{41}$ & Adalimumab & NA & 2003 & MTX & 128 & MTX experienced \\
\hline Weisman et al $2007^{42}$ & Etanercept & NA & 2000 & Placebo & 535 & MTX experienced \\
\hline Zhou et al $2007^{43}$ & Golimumab & NA & 2001 & Placebo & 36 & MTX experienced \\
\hline Durez et al $2007^{44}$ & Infliximab & NA & 2003 & MTX and prednisone & 44 & MTX naive \\
\hline Fleischmann et al $2008^{45 *}$ & Certolizumab & FAST4WARD & 2003 & Placebo & 220 & MTX experienced \\
\hline Keystone et al $2008^{46}$ & Certolizumab & RAPID1 & 2005 & MTX & 982 & MTX experienced \\
\hline Smolen et al $2008^{47 *}$ & Certolizumab & RAPID2 & 2005 & MTX & 619 & MTX experienced \\
\hline Combe et al 2008 ${ }^{48 *}$ & Etanercept & 309 & 2000 & SSZ & 254 & MTX experienced \\
\hline Emery et al $2008^{49}$ & Etanercept & COMET & 2004 & MTX & 542 & MTX naive \\
\hline Kameda et al $2008^{50}$ & Etanercept & JESMR & 2005 & MTX & 151 & MTX experienced \\
\hline Sheehy et al $2008^{51}$ & Etanercept & NA & - & MTX & 40 & MTX naive \\
\hline Wyeth data on file & Etanercept & 0881A1-319 & 2006 & MTX & 156 & MTX experienced \\
\hline Sennels et al $2008^{52}$ & Etanercept & ADORE & 2003 & Etanercept & 25 & MTX experienced \\
\hline Weinblatt et al $2008^{53}$ & Etanercept & NA & 2005 & Etanercept & 200 & MTX experienced \\
\hline Miyasaka et al $2008^{54}$ & Adalimumab & CHANGE & 2004 & Placebo & 352 & MTX experienced \\
\hline Kay et al $2008^{55}$ & Golimumab & NA & 2003 & MTX & 172 & MTX experienced \\
\hline Keystone $2008^{14}$ & Golimumab & GO-FORWARD & 2005 & MTX & 444 & MTX experienced \\
\hline Emery et al $2009^{15}$ & Golimumab & GO-BEFORE & 2005 & MTX & 634 & MTX naive \\
\hline Smolen et al $2009^{56}$ & Golimumab & GO-AFTER & 2006 & Placebo & 461 & MTX experienced \\
\hline
\end{tabular}


considered to be potentially relevant and came to a consensus on inclusion based on the inclusion criteria.

\section{Data extraction}

One reviewer examined all publications for duplication of study populations. After removing duplicates, the study characteristics, including study design, patient enrolment dates, baseline demographics, clinical characteristics and relevant clinical outcomes, were recorded for all studies. Publications were also identified as studies having either methotrexate-experienced or methotrexate-naive populations.

Unpublished study enrolment dates were obtained using the study identification number from follow-up publications, ClinicalTrials.gov, fda.gov, Trial Trove, Prous Integrity, Adis Clinical Trial and Adis R\&D Insight. If study enrolment dates were unavailable from these resources, the publication's primary authors were contacted to obtain the information. All other missing information was noted as not available and was not reported in subsequent analyses.

\section{Data analysis}

We evaluated the inclusion criteria and baseline characteristics of the patients from studies over the years. The time point for each study was the enrolment start date. The anchor time point was the earliest enrolment start date for the first study. Time points for all other studies were measured (in months) from the anchor time point. Regression analysis was used to evaluate changes in inclusion criteria and baseline characteristics over time. The hypothesis of coincidence and equality of intercept was tested for the linear models at a significance level of $\alpha<0.05$.

If baseline descriptive statistics for the total study population were not available, a weighted mean was calculated for continuous variables by multiplying the mean value for each study arm by the number of patients in the study arm, summing these values, then dividing by the total number of patients in the study.

We conducted a sensitivity analysis to account for missing enrolment dates or baseline characteristics. The mean elapsed time from enrolment start date to publication date for all studies with known values was subtracted from the publication date of studies with missing enrolment start dates to obtain an estimated enrolment start date. If the estimated enrolment start date was before the anchor enrolment start date, the anchor date was used.

Data from primary publications (those with primary endpoints) were used for subsequent analysis and study entry criteria and baseline clinical characteristics were evaluated over time for methotrexate-experienced and methotrexate-naive study populations using regression analysis.

\section{RESULTS}

A total of 2333 abstracts/manuscripts from MEDLINE, EMBASE, the Cochrane Library and other sources (bibliographies from health technology assessments, review articles, etc.) were identified. Duplicate and extraneous publications from each source were removed using Reference Manager, leaving 1407 unique manuscripts for etanercept $(n=411)$, adalimumab ( $n=412)$, infliximab ( $n=537)$, certolizumab $(n=38)$ and golimumab $(n=9)$. Figure 1 shows the results of the filtering process in which publications were selected for inclusion in the analysis. Of the 1407 unique publications obtained during the medical literature database search, 1256 were excluded because they were not double-blind, randomised, controlled studies, did not include the intervention of interest, did not include the population of interest, had less than 4 weeks of follow-up $(n=4)$ or had a sample size of fewer than 25 patients. The remaining 151 publications were retrieved for detailed evaluation. A total of 1435 abstracts were identified during the ACR and EULAR congress search. Of these, 1388 abstracts were excluded because they did not provide sufficient information, had results that were subsequently published in the peer-reviewed literature and included in the medical literature database search, were not double-blind, randomised, controlled studies; or did not evaluate anti-TNF $\alpha$ agents in RA. The remaining 47 abstracts were retrieved for more detailed evaluation.

\section{Studies of anti-TNF $\alpha$ agents}

A total of 88 double-blind, randomised, controlled studies of antiTNF $\alpha$ agents met the inclusion criteria. From these, 44 primary publications were identified that reported the results of a priori primary study endpoints, including eight adalimumab studies, four certolizumab studies, 17 etanercept studies, five golimumab studies and 10 infliximab studies (table 1). Of the primary studies, 37 were conducted in methotrexate-experienced patient populations and seven were conducted in methotrexate-naive patient populations. From these, five studies were identified that provided x-ray data for methotrexate-experienced patients and five studies provided $\mathrm{x}$-ray data for patients who were methotrexate-naive. Time anchors were Elliott et al ${ }^{16}$ (enrolment start date August 1993) for methotrexate-experienced studies, and Bathon et a ${ }^{22}$ (enrolment start date May 1997) for methotrexatenaive studies.

Table 2 Changes in inclusion criteria and baseline characteristics over time for methotrexate-experienced and methotrexate-naive populations

\begin{tabular}{|c|c|c|c|c|c|}
\hline & $\begin{array}{l}\text { No of } \\
\text { studies }\end{array}$ & Intercept & Slope & $\mathbf{R}^{2}$ & p Value \\
\hline \multicolumn{6}{|c|}{ Methotrexate-experienced populations } \\
\hline \multicolumn{6}{|l|}{ Swollen joint counts } \\
\hline \multicolumn{6}{|l|}{ Inclusion criteria } \\
\hline Base case & 26 & 7.2 & -0.0069 & 0.02 & 0.44 \\
\hline Sensitivity & 34 & 7.6 & -0.0109 & 0.06 & 0.16 \\
\hline \multicolumn{6}{|l|}{ Baseline characteristics } \\
\hline Base case & 20 & 22.2 & -0.0403 & 0.17 & 0.06 \\
\hline Sensitivity & 26 & 23.0 & -0.0468 & 0.29 & 0.00 \\
\hline \multicolumn{6}{|l|}{ Tender joint counts } \\
\hline \multicolumn{6}{|l|}{ Inclusion criteria } \\
\hline Base case & 26 & 8.6 & -0.0098 & 0.03 & 0.39 \\
\hline Sensitivity & 34 & 9.3 & -0.0150 & 0.07 & 0.12 \\
\hline \multicolumn{6}{|l|}{ Baseline characteristics } \\
\hline Base case & 19 & 29.3 & -0.0219 & 0.02 & 0.53 \\
\hline Sensitivity & 25 & 30.9 & -0.0335 & 0.07 & 0.20 \\
\hline \multicolumn{6}{|l|}{ C-reactive protein } \\
\hline \multicolumn{6}{|l|}{ Inclusion criteria } \\
\hline Base case & 17 & 1.9 & -0.0019 & 0.06 & 0.34 \\
\hline Sensitivity & 21 & 2.0 & -0.0022 & 0.10 & 0.16 \\
\hline \multicolumn{6}{|l|}{ Baseline characteristics } \\
\hline Base case & 18 & 4.8 & -0.0199 & 0.27 & 0.03 \\
\hline Sensitivity & 24 & 4.6 & -0.0182 & 0.26 & 0.01 \\
\hline \multicolumn{6}{|l|}{ Methotrexate-naive populations* } \\
\hline \multicolumn{6}{|l|}{ Swollen joint counts } \\
\hline Inclusion criteria & 5 & 10.9 & -0.0630 & 0.88 & 0.02 \\
\hline Baseline characteristics & 6 & 24.3 & -0.0974 & 0.64 & 0.05 \\
\hline \multicolumn{6}{|l|}{ Tender joint counts } \\
\hline Inclusion criteria & 5 & 13.3 & -0.0802 & 0.86 & 0.02 \\
\hline Baseline characteristics & 6 & 31.9 & -0.0869 & 0.21 & 0.36 \\
\hline \multicolumn{6}{|l|}{ C-reactive protein } \\
\hline Inclusion criteria & 5 & 1.9 & -0.0027 & 0.17 & 0.49 \\
\hline Baseline characteristics & 6 & 3.8 & -0.0059 & 0.12 & 0.49 \\
\hline
\end{tabular}

Data from base case and sensitivity analysis are shown.

* Sensitivity analyses were unnecessary because enrolment start dates were available for all studies. 
Potentially relevant $2,333 \mathrm{RCTs}$ identified from literature search and screened for retrieval.

After removing duplicates $\mathrm{n}=1,407$

Excluded: $n=1,256$ Not DB RCTs:

Not intervention of interest;

Not population of interest; $<4$ weeks duration;

sample size $<25$ other inclusion/exclusion criteria
Potentially relevant RCTs identified from ACR/EULAR Abstracts and screened for retrieval $n=1,435$

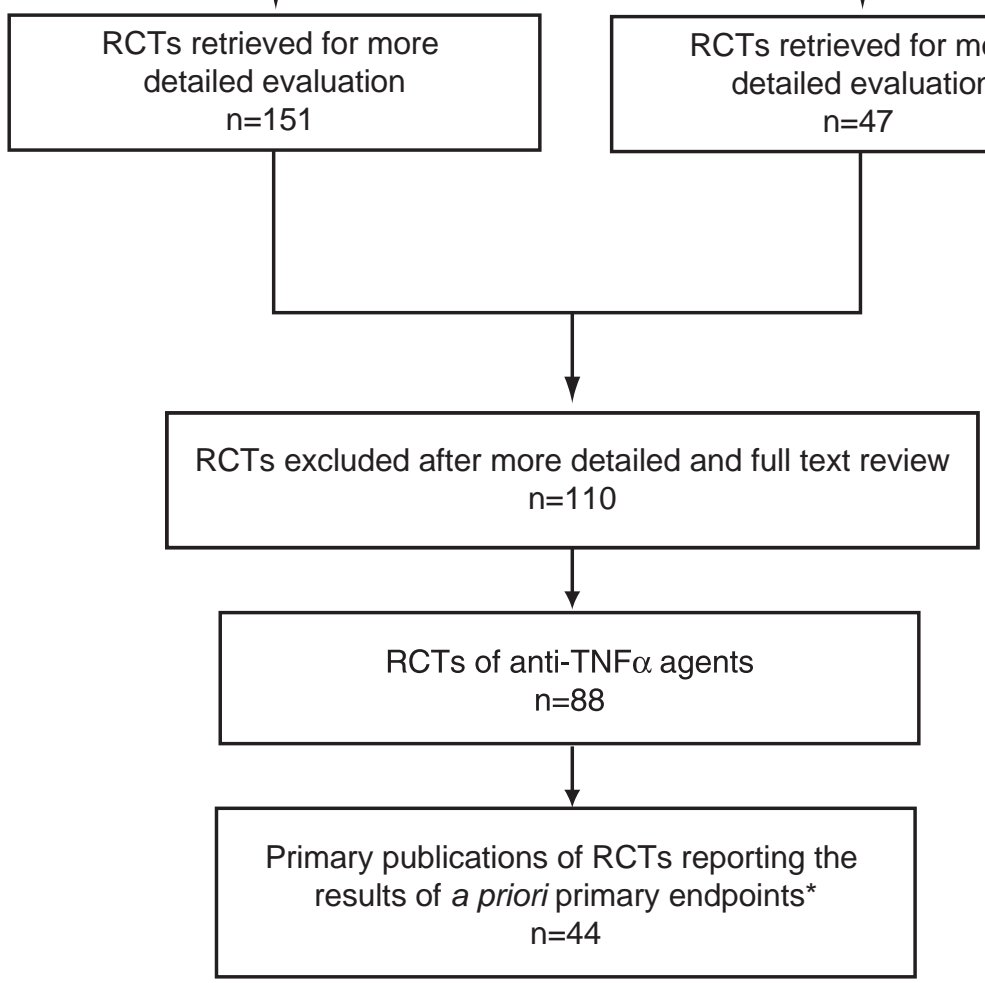

Figure 1 Results of literature search and process of eliminating publications. *two clinical study reports that were included for golimumab. These studies have since been published. ${ }^{14}{ }^{15}$ ACR, American College of Rheumatology; DB, double blind; EULAR, European League Against Rheumatism; RCT, randomised controlled trial; TNF, Tumour necrosis factor.

Table 2 summarises the changes in inclusion criteria and baseline characteristics over time for anti-TNF $\alpha$ studies in methotrexate-experienced and methotrexate-naive patient populations.

In the studies with methotrexate-experienced populations, no significant difference over time was observed in any inclusion criteria (tender or swollen joint counts or $\mathrm{C}$-reactive protein (CRP; figure 2). However, significant decreases (or trends) over time were observed in baseline swollen joint count ( $\mathrm{p}=0.06$, $\mathrm{R}^{2}=0.17$; figure $\left.2 \mathrm{~B}\right)$ and $C R P\left(\mathrm{p}=0.03, \mathrm{R}^{2}=0.27\right.$; figure $\left.2 \mathrm{~F}\right)$, but not in baseline tender joint counts (figure 2D). Sensitivity analyses confirmed the findings in the base case for each measurement.

In the studies with methotrexate-naive populations, significant decreases over time were observed in swollen joint inclusion criteria ( $p=0.02, R^{2}=0.88$; figure $3 A$ ) and mean baseline swollen joint count $\left(p=0.05, R^{2}=0.64\right.$; figure $3 B$ ) and tender joint inclusion criteria ( $p=0.02, R^{2}=0.86$; figure $3 C$ ), but not in baseline tender joint count, CRP or CRP inclusion criteria (figure 3D-F). Sensitivity analyses were unnecessary because enrolment start dates were available for all methotrexate-naive studies.

In the five studies of methotrexate-experienced patients that included x-ray data, the mean baseline Sharp or van der Heijde modified Sharp score decreased significantly over time $(p=0.01$, $\mathrm{R}^{2}=0.93$; figure $4 \mathrm{~A}$ ). Indeed, numerically this difference was quite dramatic, accounting for more than a $50 \%$ reduction over approximately 10 years. There was no significant decline in the mean baseline van der Heijde modified Sharp score in the studies of methotrexate-naive patients $\left(p=0.90, R^{2}=0.01\right.$; figure $\left.4 B\right)$. Annual radiographic progression (another measure of disease severity) for each of these studies was estimated by dividing the mean baseline Sharp or van der Heijde modified Sharp score by the mean disease duration. This estimated progression was then 

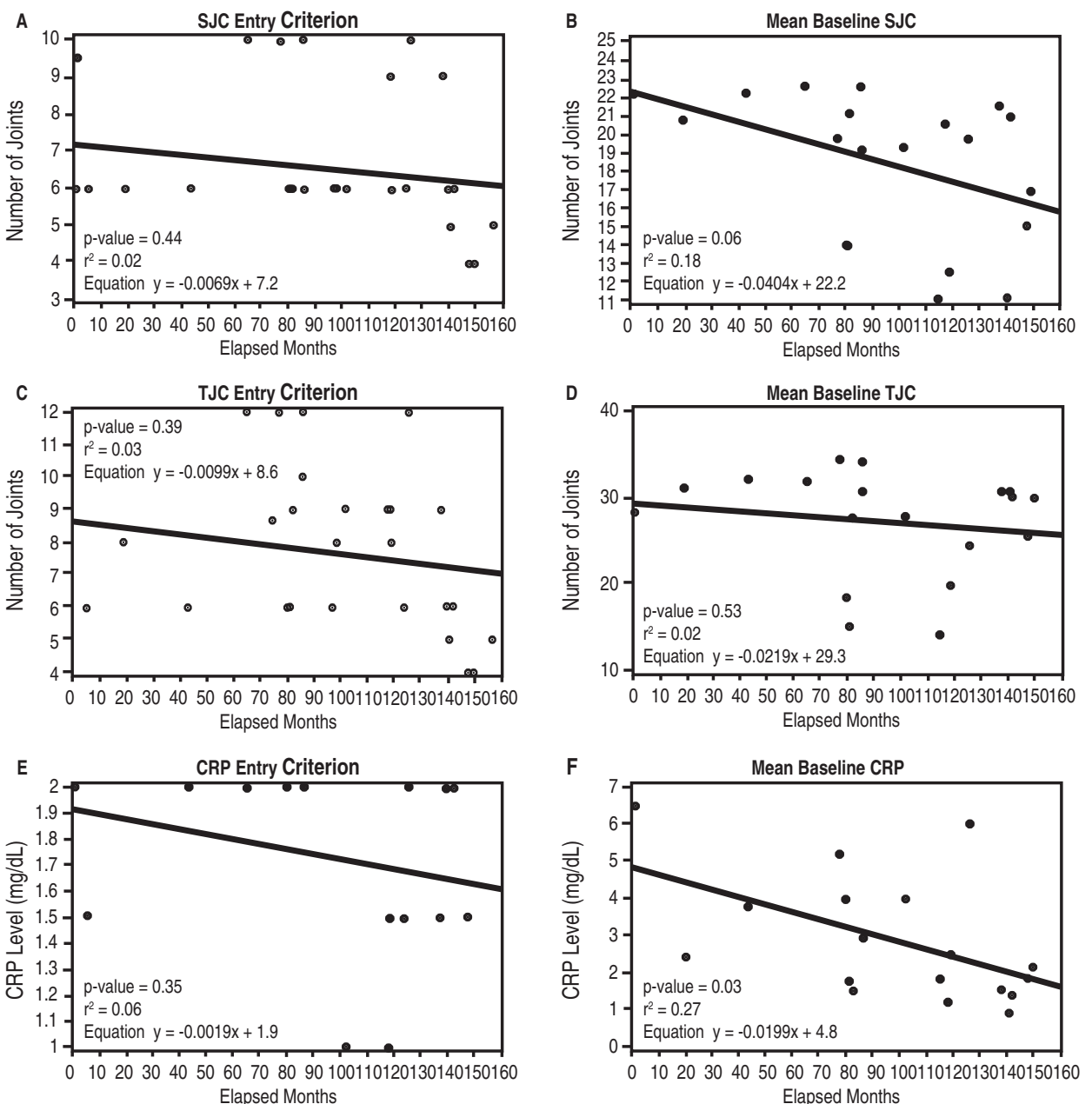

Figure 2 Results for entry criteria and actual mean baseline values in methotrexate-experienced patients over time. CRP, C-reactive protein; SJC, swollen joint count; TJC, tender joint count.

compared with the actual progression observed in the control (methotrexate \pm placebo) group for each of the trials at 52 weeks. Comparisons were made for methotrexate-experienced and methotrexate-naive studies separately (figure 5A,B). While the annualised progression rates did not show a consistent pattern over the years, the actual progression observed over 1 year in the control groups was much lower than the estimated annualised progression rate for the more recent trials. The annualised progression rate, which predicted progression rate very well in control groups in older trials like ATTRACT and others, ${ }^{57-60}$ does not seem to predict the progression rate in the control groups at all in the more recent trials.

\section{DISCUSSION}

The results of this study show that the characteristics of patients who were enrolled in studies of TNF $\alpha$ inhibitors in RA have changed over the years. Since 1993, with the first randomised, controlled study of an anti-TNF $\alpha$ agent, disease characteristics of patients who participate in these studies have become generally less severe. Among patients in methotrexate-experienced studies, significant decreases in baseline swollen joint count and CRP were observed. The most dramatic change was seen in baseline radiographic scores, which decreased by more than $50 \%$ over just one decade. This change relates to both baseline scores and estimated annual progression rates and has been suggested by others. ${ }^{57-60}$ Despite these observations, the determination of whether these changes are clinically meaningful is beyond the scope of the current study.

In line with the decline in swollen joint count and CRP at baseline, which are the major variables associated with the progression of joint damage, ${ }^{61} 62$ these data suggest that the standard of care (for the pool of patients from which clinical trial patients are obtained) has improved during the past decade. ${ }^{63}$ The decrease in baseline disease characteristics was less pronounced in the methotrexate-naive (early RA) population than the methotrexate-experienced (more established and longer standing disease) population, an observation suggesting that the general characteristics of RA at presentation may not have changed over the years. Methotrexate-naive early RA patients may reflect the clinical characteristics of RA at presentation/ diagnosis more closely with minimal influence of treatments received, whereas the clinical characteristics of more established methotrexate-experienced RA patients may be influenced by the treatments received. The changes in the clinical characteristics of patients being enrolled in randomised clinical trials may thus be more of a function of improved standard of care and change in the treatment paradigm of RA (for the pool of patients from which clinical trial patients are recruited). However, while changes in demographics and general health aspects may contribute to less severe disease, ${ }^{12}$ better care for patients with RA may be the major reason for this observation. ${ }^{9}$ Other possibilities must also be considered; for example, investigative sites are 

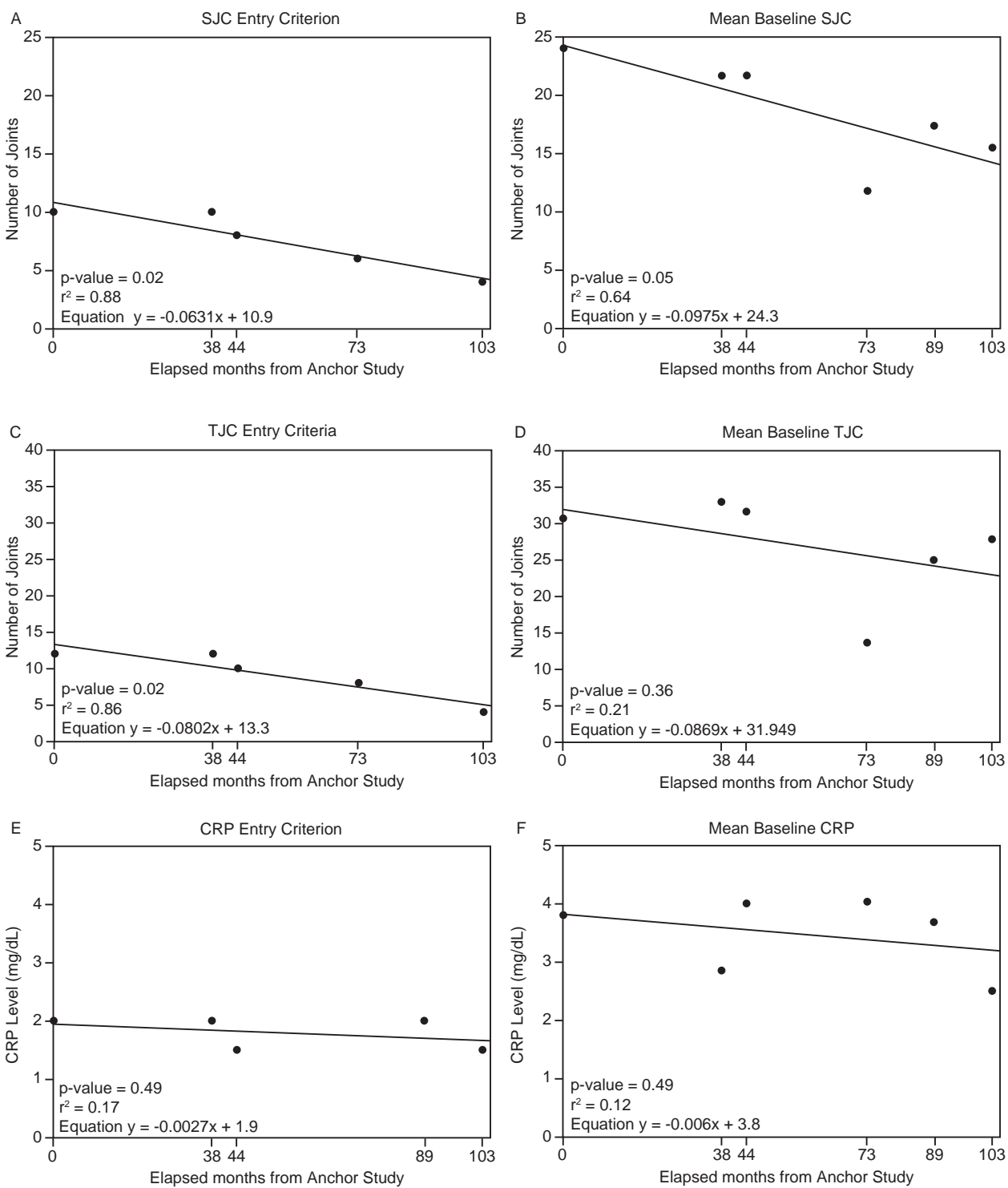

Figure 3 Results for entry criteria and actual mean baseline values in methotrexate-naive patients over time. CRP, C-reactive protein; SJC, swollen joint count; TJC, tender joint count.

\section{A}

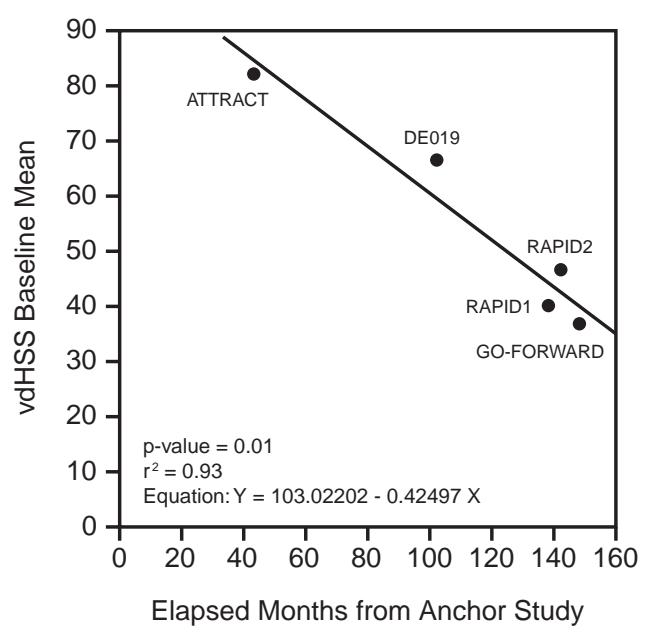

B

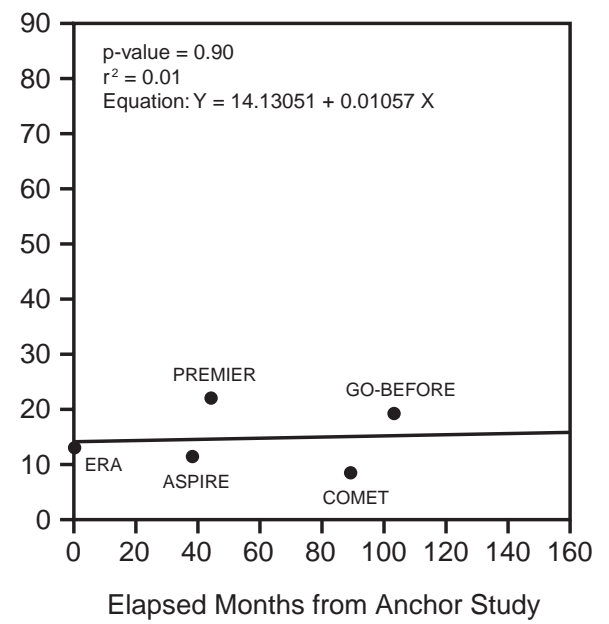

Figure 4 Results for change in mean baseline total Sharp or van der Heijde modified Sharp score over time (months elapsed since anchor study) for (A) Methotrexate-experienced (anchor study 1993) and (B) Methotrexate-naive (anchor study 1997) patients. vdHSS, van der Heijde Sharp score. 


\section{A Radiographic progression in MTX-experienced studies}

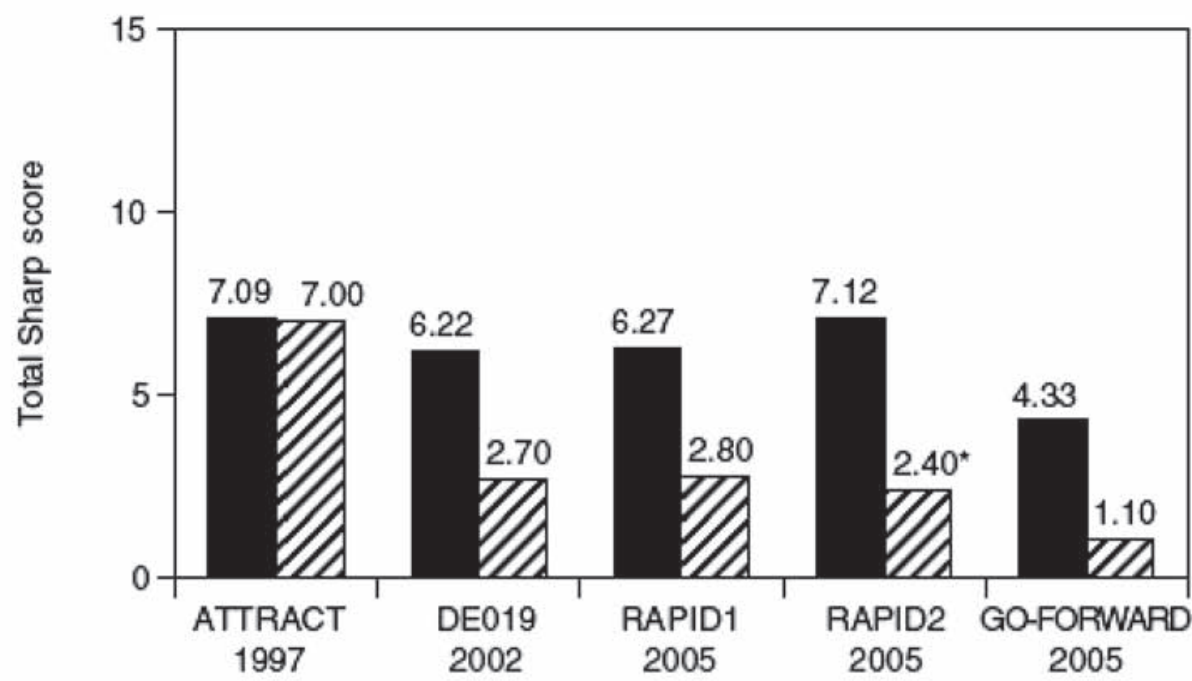

B Radiographic progression in MTX-naive studies

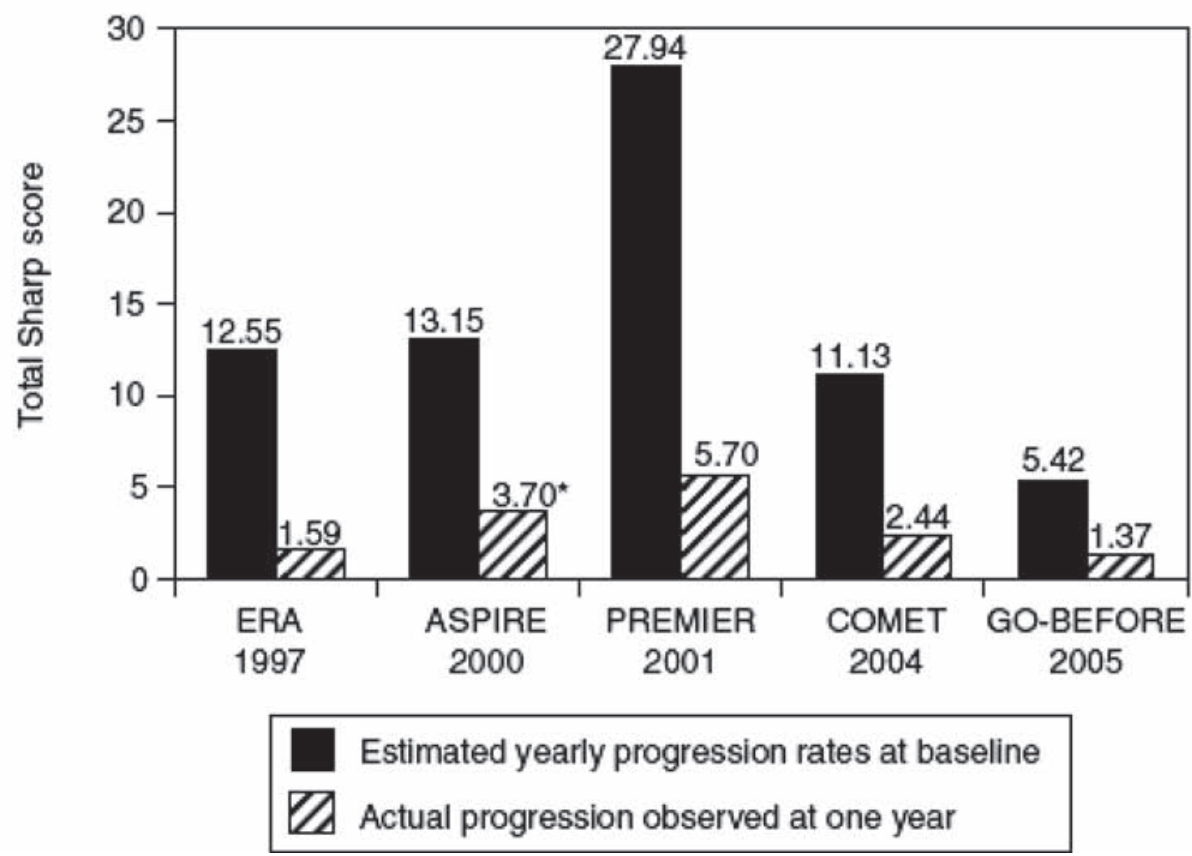

Figure 5 Estimated yearly progression versus actual radiographic progression at week 52 in methotrexate (MTX)-experienced (*actual 1 year values in the RAPID2 and GO-FORWARD study were measured at week 24 and extrapolated (doubled) to 1 year) and methotrexate-naive studies ( ${ }^{*}$ actual radiographic progression (at 1 year) was measured at week 54 in the ASPIRE study and week 52 in all other studies).

recruiting higher proportions of patients with less severe disease to meet the demands of an increased number of clinical trials being conducted, the changing geographical distribution of clinical trial sites, etc. However, the current study did not allow for the assessment of such possibilities.

There are several limitations to our study. First, we focused on TNF $\alpha$ inhibitors rather than on all clinical trials performed during the time of observation. However, the more recent randomised controlled trials for abatacept, rituximab and tocilizumab ${ }^{64-66}$ employed the Genant-modified Sharp score, which has a much lower total value than the Sharp or van der Heijde modified Sharp score ${ }^{64}$ and, therefore, comparability would be impaired. Moreover, the inclusion of data from the studies of newer TNF $\alpha$ inhibitors, including certolizumab and golimumab, 144662 ensured the integration of studies performed at the same time period as these other trials. Second, the number of studies on early RA patients was much smaller than on established RA patients with inadequate response to methotrexate; consequently, the interpretation of these data has to be seen with the respective caution. Third, we did not assess publications from registries; however, patients evaluated in registries, while constituting 'real life patients', are of much broader range, do not have to fulfil trial-like inclusion criteria, are dependent on the reimbursement status in the individual countries, and are thus more heterogeneous. Fourth, the geographic distribution of patients was not reported consistently in detail in the manuscripts reviewed. 
Although clinical trials are currently being conducted in more regions and countries compared with the previous decade, due to the unavailability of consistent data from all studies reviewed, we were not able to evaluate the change in geographic distribution of patients in these studies. Fifth, a majority of the studies included in these analyses did not provide adequate and consistent data regarding duration of disease, which limited the assessment of changes in disease duration of patients enrolled in clinical trials over the years. However, the limited data available to be analysed did not show any specific pattern in disease duration over the years. Disease duration of RA has been shown to impact clinical characteristics and responsiveness to treatment by others. ${ }^{67}$ Finally, the patient populations studied are from randomised clinical trials; and thus, the changes observed over 16 years may reflect the changes in patient populations of investigative sites looking for patients fulfilling inclusion criteria for clinical trials rather than the entire RA population, at least for sites in the US, Canada and western Europe. 6368

Despite the limitations, the trends described above have several implications. They suggest that the overall disease characteristics of the population of patients with RA from which these subjects are recruited have become less severe over the years. During the time period of this study, the standard of care (treatment paradigm) of RA has changed, emphasising the earlier diagnosis and earlier and more intensive use of combination therapy, ${ }^{6970}$ which results in fewer patients with persistent severe disease activity and advanced disability. We also acknowledge that trial centres that have limited access to biological therapies have improved their therapeutic approaches to RA by virtue of the many studies published on the advantage of early and intensive therapy. Indeed, mean methotrexate doses have increased when compared with the anchor study, ${ }^{16}$ and studies of methotrexate-naive patients have employed much higher doses than were used in the anchor study ${ }^{22}$ or studies published around the same time on leflunomide trials. ${ }^{71}$ In line with this, the results of long-term observational studies have suggested that the health status of patients with RA has improved. ${ }^{9} 12$

Whereas multiple factors may be responsible for this change in the patient populations enrolled in clinical trials for RA, the change in standard of care for RA may be the single most important factor. The standard of care now emphasises early intensive treatment, and RA patients receive methotrexate earlier and in higher doses than patients did more than a decade ago, during the clinical trials for etanercept and infliximab. The changes in the treatment paradigm for RA, coupled with the changes in the populations of patients enrolled in clinical trials should be considered when reviewing new studies on all therapies for RA. These changes in the baseline characteristics will also need to be considered when designing clinical trials in RA. They also have to be accounted for when performing meta-analyses of clinical trials. ${ }^{72}$

Acknowledgements The authors thank the patients, investigators and study personnel who made these trials possible. The authors thank Kirsten Schuck and Mary Whitman, PhD, of Centocor Ortho Biotech Inc, a wholly owned subsidiary of Johnson \& Johnson, and Scott Newcomer of Cephalon, formerly of Centocor Ortho Biotech, who helped prepare the manuscript.

Funding This study was funded by Johnson \& Johnson.

Competing interests MUR, JB, MKD, ECH, TG and SP were all employees of Johnson \& Johnson at the time of the study and own Johnson \& Johnson stock options. ELM has been a paid consultant and advisory board member and is an investigator for Johnson \& Johnson/Centocor. PGC has received consulting fees, speaking fees and/or research grants from Astra Zeneca, Bristol-Myers Squibb, Centocor; Merck, Sharpe and Dohme, Novartis, Roche and Pfizer. EK has received funding research from Abbot Laboratories, Amgen, AstraZeneca Pharmaceuticals LP, Bristol-Myers Squibb, Centocor, F. Hoffman-LaRoche, Novartis Pharmaceuticals
Schering-Plough Corporation, UCB and Wyeth Pharmaceuticals. He has consulting agreements/advisory board memberships with Abbott Laboratories, Amgen, BristolMyers Squibb Company, Centocor, F. Hoffman-LaRoche, Genentech, Schering-Plough Corporation, UCB and Pfizer Pharmaceuticals. He has speaker honoraria agreements with Abbott Laboratories, Amgen, Bristol-Myers Squibb Company, F. HoffmanLaRoche, Schering-Plough Corporation and Pfizer Pharmaceuticals. JSS has received grant support from and/or provided expert advice to Abbott, Amgen, BMS, Centocor, MSD, Pfizer, Roche, UCB and Sanofi-Aventis. DA and DvdH have nothing to declare.

Provenance and peer review Not commissioned; externally peer reviewed.

\section{REFERENCES}

1. Wilske KR, Healey LA. Challenging the therapeutic pyramid: a new look at treatment strategies for rheumatoid arthritis. J Rheumatol Supp/ 1990;25:4-7.

2. Buchan G, Barrett $\mathrm{K}$, Turner $\mathrm{M}$, et al. Interleukin-1 and tumour necrosis factor mRNA expression in rheumatoid arthritis: prolonged production of IL-1 alpha. Clin Exp Immunol 1988;73:449-55.

3. Chu CQ, Field M, Feldmann M, et al. Localization of tumor necrosis factor alpha in synovial tissues and at the cartilage-pannus junction in patients with rheumatoid arthritis. Arthritis Rheum 1991;34:1125-32.

4. Elliott MJ, Maini RN, Feldmann M, et al. Treatment of rheumatoid arthritis with chimeric monoclonal antibodies to tumor necrosis factor alpha. Arthritis Rheum 1993;36:1681-90.

5. Emery P, Salmon M. Early rheumatoid arthritis: time to aim for remission? Ann Rheum Dis 1995;54:944-7.

6. van der Heide A, Jacobs JW, Bijlsma JW, et al. The effectiveness of early treatment with 'second-line' antirheumatic drugs. A randomized, controlled trial. Ann Intern Med 1996;124:699-707.

7. van Vollenhoven RF. New and future agents in the treatment of rheumatoid arthritis. Discov Med 2010;9:319-27.

8. Osiri M, Shea B, Robinson V, et al. Leflunomide for the treatment of rheumatoid arthritis: a systematic review and metaanalysis. J Rheumatol 2003;30:1182-90.

9. Uhlig T, Kvien TK. Is rheumatoid arthritis really getting less severe? Nat Rev Rheumatol 2009:5:461-4.

10. van Vollenhoven RF, Klareskog $L$. The treatment of rheumatoid arthritis: getting better all the time? Arthritis Rheum 2005:52:991-4.

11. Pincus T, Sokka T, Kautiainen H. Patients seen for standard rheumatoid arthritis care have significantly better articular, radiographic, laboratory, and functional status in 2000 than in 1985. Arthritis Rheum 2005;52:1009-19.

12. Uhlig T, Heiberg T, Mowinckel $P$, et al. Rheumatoid arthritis is milder in the new millennium: health status in patients with rheumatoid arthritis 1994-2004. Ann Rheum Dis 2008;67:1710-15.

13. Pincus T, Sokka T, Chung CP, et al. Declines in number of tender and swollen joints in patients with rheumatoid arthritis seen in standard care in 1985 versus 2001: possible considerations for revision of inclusion criteria for clinical trials. Ann Rheum Dis 2006;65:878-83.

14. Keystone EC, Genovese MC, Klareskog L, et al.; GO-FORWARD Study. Golimumab, a human antibody to tumour necrosis factor \{alpha\} given by monthly subcutaneous injections, in active rheumatoid arthritis despite methotrexate therapy: the GO-FORWARD Study. Ann Rheum Dis 2009;68:789-96.

15. Emery P, Fleischmann RM, Moreland LW, et al. Golimumab, a human anti-tumor necrosis factor alpha monoclonal antibody, injected subcutaneously every four weeks in methotrexate-naive patients with active rheumatoid arthritis: twenty-four-week results of a phase III, multicenter, randomized, double-blind, placebo-controlled study of golimumab before methotrexate as first-line therapy for early-onset rheumatoid arthritis. Arthritis Rheum 2009:60:2272-83.

16. Elliott MJ, Maini RN, Feldmann M, et al. Randomised double-blind comparison of chimeric monoclonal antibody to tumour necrosis factor alpha (cA2) versus placebo in rheumatoid arthritis. Lancet 1994;344:1105-10.

17. Moreland LW, Baumgartner SW, Schiff MH, et al. Treatment of rheumatoid arthritis with a recombinant human tumor necrosis factor receptor (p75)-Fc fusion protein. N Engl J Med 1997;337:141-7.

18. Maini RN, Breedveld FC, Kalden JR, et al. Therapeutic efficacy of multiple intravenous infusions of anti-tumor necrosis factor alpha monoclonal antibody combined with low-dose weekly methotrexate in rheumatoid arthritis. Arthritis Rheum 1998;41:1552-63.

19. Maini R, St Clair EW, Breedveld F, et al. Infliximab (chimeric anti-tumour necrosis factor alpha monoclonal antibody) versus placebo in rheumatoid arthritis patients receiving concomitant methotrexate: a randomised phase III trial. ATTRACT Study Group. Lancet 1999;354:1932-9.

20. Moreland LW, Schiff MH, Baumgartner SW, et al. Etanercept therapy in rheumatoid arthritis. A randomized, controlled trial. Ann Intern Med 1999;130:478-86.

21. Weinblatt ME, Kremer JM, Bankhurst AD, et al. A trial of etanercept, a recombinant tumor necrosis factor receptor:Fc fusion protein, in patients with rheumatoid arthritis receiving methotrexate. N Engl J Med 1999;340:253-9.

22. Bathon JM, Martin RW, Fleischmann RM, et al. A comparison of etanercept and methotrexate in patients with early rheumatoid arthritis. N Engl J Med 2000:343:1586-93. 
23. Kavanaugh A, St Clair EW, McCune WJ, et al. Chimeric anti-tumor necrosis factoralpha monoclonal antibody treatment of patients with rheumatoid arthritis receiving methotrexate therapy. J Rheumatol 2000;27:841-50.

24. Choy EH, Hazleman B, Smith M, et al. Efficacy of a novel PEGylated humanized anti-TNF fragment (CDP870) in patients with rheumatoid arthritis: a phase II doubleblinded, randomized, dose-escalating trial. Rheumatology (Oxford) 2002;41:1133-7.

25. Furst DE, Schiff MH, Fleischmann RM, et al. Adalimumab, a fully human anti tumor necrosis factor-alpha monoclonal antibody, and concomitant standard antirheumatic therapy for the treatment of rheumatoid arthritis: results of STAR (Safety Trial of Adalimumab in Rheumatoid Arthritis). J Rheumatol 2003;30:2563-71.

26. van de Putte LB, Rau R, Breedveld FC, et al. Efficacy and safety of the fully human anti-tumour necrosis factor alpha monoclonal antibody adalimumab (D2E7) in DMARD refractory patients with rheumatoid arthritis: a 12 week, phase II study. Ann Rheum Dis 2003;62:1168-77.

27. Weinblatt ME, Keystone EC, Furst DE, et al. Adalimumab, a fully human anti-tumor necrosis factor alpha monoclonal antibody, for the treatment of rheumatoid arthritis in patients taking concomitant methotrexate: the ARMADA trial. Arthritis Rheum 2003; 48:35-45.

28. Keystone EC, Kavanaugh AF, Sharp JT, et al. Radiographic, clinical, and functional outcomes of treatment with adalimumab (a human anti-tumor necrosis factor monoclonal antibody) in patients with active rheumatoid arthritis receiving concomitant methotrexate therapy: a randomized, placebo-controlled, 52-week trial. Arthritis Rheum 2004;50:1400-11.

29. van de Putte LB, Atkins C, Malaise M, et al. Efficacy and safety of adalimumab as monotherapy in patients with rheumatoid arthritis for whom previous disease modifying antirheumatic drug treatment has failed. Ann Rheum Dis 2004;63:508-16.

30. Genovese MC, Kremer JM. Treatment of rheumatoid arthritis with etanercept. Rheum Dis Clin North Am 2004;30:311-28, vi-vii.

31. Keystone EC, Schiff MH, Kremer JM, et al. Once-weekly administration of $50 \mathrm{mg}$ etanercept in patients with active rheumatoid arthritis: results of a multicenter, randomized, double-blind, placebo-controlled trial. Arthritis Rheum 2004;50:353-63.

32. Klareskog L, van der Heijde DM, de Jager JP, et al.; TEMPO (Trial of Etanercept and Methotrexate with Radiographic Patient Outcomes) study investigators. Therapeutic effect of the combination of etanercept and methotrexate compared with each treatment alone in patients with rheumatoid arthritis: double-blind randomised controlled trial. Lancet 2004;363:675-81.

33. Lan JL, Chou SJ, Chen DY, et al. A comparative study of etanercept plus methotrexate and methotrexate alone in Taiwanese patients with active rheumatoid arthritis: a 12-week, double-blind, randomized, placebo-controlled study. J Formos Med Assoc 2004;103:618-23.

34. St Clair EW, van der Heijde DM, Smolen JS, et al.; Active-Controlled Study of Patients Receiving Infliximab for the Treatment of Rheumatoid Arthritis of Early Onset Study Group. Combination of infliximab and methotrexate therapy for early rheumatoid arthritis: a randomized, controlled trial. Arthritis Rheum 2004;50:3432-43.

35. Johnsen AK, Schiff MH, Mease PJ, et al. Comparison of 2 doses of etanercept (50 vs $100 \mathrm{mg}$ ) in active rheumatoid arthritis: a randomized double blind study. $J$ Rheumatol 2006;33:659-64.

36. Abe T, Takeuchi T, Miyasaka N, et al. A multicenter, double-blind, randomized, placebo controlled trial of infliximab combined with low dose methotrexate in Japanese patients with rheumatoid arthritis. J Rheumatol 2006;33:37-44.

37. Leirisalo-Repo M, Mottonen T, Hannonen P, et al. Presentation: does addition of infliximab to triple DMARD plus prednisolone therapy increase rate of remissions in patients with early active arthritis? A randomized double-blind placebo controlled study. American College of Rheumatology, 2006.

38. Westhovens R, Yocum D, Han J, et al.; START Study Group. The safety of infliximab, combined with background treatments, among patients with rheumatoid arthritis and various comorbidities: a large, randomized, placebo-controlled trial. Arthritis Rheum 2006; 54:1075-86.

39. Zhang F-C, Hou Y, Huang F, et al. Infliximab versus placebo in rheumatoid arthritis patients receiving concomitant methotrexate: a preliminary study from China. APLAR J Rheumatol 2006;2:127-30.

40. Breedveld FC, Weisman MH, Kavanaugh AF, et al. The PREMIER study: a multicenter, randomized, double-blind clinical trial of combination therapy with adalimumab plus methotrexate versus methotrexate alone or adalimumab alone in patients with early, aggressive rheumatoid arthritis who had not had previous methotrexate treatment. Arthritis Rheum 2006;54:26-37.

41. Kim H-Y, Lee S-K, Song Y, et al. A randomized, double-blind, placebo-controlled, phase III study of the human anti-tumor necrosis factor antibody adalimumab administered as subcutaneous injections in Korean rheumatoid arthritis patients treated with methotrexate. APLAR J Rheumatol 2007;10:9-16.

42. Weisman MH, Paulus HE, Burch FX, et al. A placebo-controlled, randomized, double-blinded study evaluating the safety of etanercept in patients with rheumatoid arthritis and concomitant comorbid diseases. Rheumatology (Oxford) 2007:46:1122-5

43. Zhou H, Jang H, Fleischmann RM, et al. Pharmacokinetics and safety of golimumab, a fully human anti-TNF-alpha monoclonal antibody, in subjects with rheumatoid arthritis. J Clin Pharmacol 2007:47:383-96.
44. Durez P, Malghem J, Nzeusseu Toukap A, et al. Treatment of early rheumatoid arthritis: a randomized magnetic resonance imaging study comparing the effects of methotrexate alone, methotrexate in combination with infliximab, and methotrexate in combination with intravenous pulse methylprednisolone. Arthritis Rheum 2007:56:3919-27.

45. Fleischmann R, Vencovsky J, van Vollenhoven RF, et al. Efficacy and safety of certolizumab pegol monotherapy every 4 weeks in patients with rheumatoid arthritis failing previous disease-modifying antirheumatic therapy: the FAST4WARD study. Ann Rheum Dis 2009;68:805-11.

46. Keystone E, van der Heijde DM, Mason D, Jr et al. Certolizumab pegol plus methotrexate is significantly more effective than placebo plus methotrexate in active rheumatoid arthritis: findings of a fifty-two-week, phase III, multicenter, randomized, double-blind, placebo-controlled, parallel-group study. Arthritis Rheum 2008;58:3319-29,

47. Smolen J, Landewé RB, Mease P, et al. Efficacy and safety of certolizumab pegol plus methotrexate in active rheumatoid arthritis: the RAPID 2 study. A randomised controlled trial. Ann Rheum Dis 2009;68:797-804.

48. Combe B, Codreanu C, Fiocco U, et al.; Etanercept European Investigators Network. Efficacy, safety and patient-reported outcomes of combination etanercept and sulfasalazine versus etanercept alone in patients with rheumatoid arthritis: a doubleblind randomised 2-year study. Ann Rheum Dis 2009;68:1146-52.

49. Emery P, Breedveld FC, Hall S, et al. Comparison of methotrexate monotherapy with a combination of methotrexate and etanercept in active, early, moderate to severe rheumatoid arthritis (COMET): a randomised, double-blind, parallel treatment trial. Lancet 2008;372:375-82.

50. Kameda H, Ueki Y, Saito K, et al. The comparison of efficacy and safety between etanercept (ETN) plus methotrexate (MTX) combination therapy and ETN monotherapy in MTX-refractory Japanese patients with rheumatoid arthritis: 52-week clinical results from the JESMR Study. Program and abstracts of the American College of Rheumatology (ACR) 2008 Annual Scientific Meeting, October 2008, San Francisco, California, USA

51. Sheehy C, Murphy E, Duffy T. Presentation: remission induction with etanercept and methotrexate in very early rheumatoid arthritis with sustained remission after etanercept withdrawal. American College of Rheumatology, 2008.

52. Sennels H, Sørensen S, Ostergaard M, et al. Circulating levels of osteopontin, osteoprotegerin, total soluble receptor activator of nuclear factor-kappa B ligand, and high-sensitivity C-reactive protein in patients with active rheumatoid arthritis randomized to etanercept alone or in combination with methotrexate. Scand J Rheumatol 2008;37:241-7.

53. Weinblatt ME, Schiff MH, Ruderman EM, et al. Efficacy and safety of etanercept $50 \mathrm{mg}$ twice a week in patients with rheumatoid arthritis who had a suboptimal response to etanercept $50 \mathrm{mg}$ once a week: results of a multicenter, randomized, double-blind, active drug-controlled study. Arthritis Rheum 2008;58:1921-30.

54. Miyasaka N, ; CHANGE Study Investigators. Clinical investigation in highly diseaseaffected rheumatoid arthritis patients in Japan with adalimumab applying standard and general evaluation: the CHANGE study. Mod Rheumatol 2008;18:252-62.

55. Kay J, Matteson EL, Dasgupta B, et al. Golimumab in patients with active rheumatoid arthritis despite treatment with methotrexate: a randomized, doubleblind, placebo-controlled, dose-ranging study. Arthritis Rheum 2008;58:964-75.

56. Smolen JS, Kay J, Doyle MK, et al.; GO-AFTER study investigators. Golimumab in patients with active rheumatoid arthritis after treatment with tumour necrosis factor alpha inhibitors (GO-AFTER study): a multicentre, randomised, double-blind, placebocontrolled, phase III trial. Lancet 2009;374:210-21.

57. Lipsky PE, van der Heijde DM, St Clair EW, et al.; Anti-Tumor Necrosis Factor Trial in Rheumatoid Arthritis with Concomitant Therapy Study Group. Infliximab and methotrexate in the treatment of rheumatoid arthritis. Anti-Tumor Necrosis Factor Trial in Rheumatoid Arthritis with Concomitant Therapy Study Group. N Engl J Med 2000;343:1594-602.

58. Strand V, Sharp JT. Radiographic data from recent randomized controlled trials in rheumatoid arthritis: what have we learned? Arthritis Rheum 2003;48:21-34.

59. Jiang $\mathbf{Y}$, Genant HK, Watt I, et al. A multicenter, double-blind, dose-ranging, randomized, placebo-controlled study of recombinant human interleukin-1 receptor antagonist in patients with rheumatoid arthritis: radiologic progression and correlation of Genant and Larsen scores. Arthritis Rheum 2000;43:1001-9.

60. Strand V, Sokolove J. Randomized controlled trial design in rheumatoid arthritis: the past decade. Arthritis Res Ther 2009:11:205.

61. van Leeuwen MA, van der Heijde DM, van Rijswijk MH, et al. Interrelationship of outcome measures and process variables in early rheumatoid arthritis. A comparison of radiologic damage, physical disability, joint counts, and acute phase reactants. $J$ Rheumatol 1994;21:425-9.

62. Smolen JS, Han C, van der Heijde DM, et al.; Active-Controlled Study of Patients Receiving Infliximab for the Treatment of Rheumatoid Arthritis of Early Onset (ASPIRE) Study Group. Radiographic changes in rheumatoid arthritis patients attaining different disease activity states with methotrexate monotherapy and infliximab plus methotrexate: the impacts of remission and tumour necrosis factor blockade. Ann Rheum Dis 2009;68:823-7.

63. Sokka T, Pincus T. Most patients receiving routine care for rheumatoid arthritis in 2001 did not meet inclusion criteria for most recent clinical trials or american college of rheumatology criteria for remission. J Rheumatol 2003;30:1138-46. 
64. Genant HK, Peterfy CG, Westhovens R et al. Abatacept inhibits progression of structural damage in rheumatoid arthritis: results from the long-term extension of the AlM trial. Ann Rheum Dis 2008;67:1084-9.

65. Cohen SB, Emery P, Greenwald MW, et al.; REFLEX Trial Group. Rituximab for rheumatoid arthritis refractory to anti-tumor necrosis factor therapy: results of a multicenter, randomized, double-blind, placebo-controlled, phase III trial evaluating primary efficacy and safety at twenty-four weeks. Arthritis Rheum 2006;54:2793-806.

66. Fleischmann R, Burgos-Vargas R, Ambs P, et al. LTTHE: tocilizumab inhibits radiographic progression and improves physical function in rheumatoid arthritis (RA) patients (Pts) at 2 yrs with increasing clinical efficacy over time. Arthritis Rheum 2009;60:637.

67. Anderson JJ, Wells G, Verhoeven AC, et al. Factors predicting response to treatment in rheumatoid arthritis: the importance of disease duration. Arthritis Rheum 2000;43:22-9.
68. Sokka T, Pincus T. Eligibility of patients in routine care for major clinical trials of anti-tumor necrosis factor alpha agents in rheumatoid arthritis. Arthritis Rheum 2003;48:313-18.

69. Weinblatt ME. Rheumatoid arthritis: treat now, not later! Ann Intern Med 1996;124:773-4.

70. Irvine S, Munro R, Porter D. Early referral, diagnosis, and treatment of rheumatoid arthritis: evidence for changing medical practice. Ann Rheum Dis 1999;58:510-13.

71. Strand V, Cohen S, Schiff M, et al. Treatment of active rheumatoid arthritis with leflunomide compared with placebo and methotrexate. Leflunomide Rheumatoid Arthritis Investigators Group. Arch Intern Med 1999;159:2542-50.

72. Smolen JS. Pharmacotherapy: how well can we compare different biologic agents for RA? Nat Rev Rheumatol 2010;6:247-8. 